\title{
County Poverty: The Case Of Los Angeles
}

Robert G. Mogull, (E-mail: mogullr@csus.edu), California State University, Sacramento

\begin{abstract}
This study serves two purposes. First, it demonstrates a method of estimating and projecting annual poverty at the sub-national level. Data obtained from decennial censuses provide the benchmarks from which poverty is estimated and projected for various demographic groups. Projections are based upon curvilinear trends both of rates and of counts for each group. The methodology can be easily applied in a variety of jurisdictional settings and levels. The second objective is to provide a specific portrait of poverty by demographic group within the County of Los Angeles. The evidence indicates a substantial increase over the next decade both in the incidence of poverty and in the number of impoverished residents. The primary source of County poverty is the growth in its Hispanic community.
\end{abstract}

\section{Background}

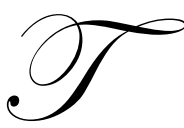

he U.S. Bureau of the Census provides two principal estimates of poverty. Both have been conducted since 1960 (for poverty since 1959) and both are widely used in academia, in commerce, by advocacy groups and by governmental agencies at all jurisdictional levels.

One source of official poverty statistics is the Current Population Surveys (CPS). These are conducted annually during the month of March and consist of supplemental questions to their usual monthly surveys of employment and unemployment (for the Bureau of Labor Statistics). The nationwide CPS reaches approximately 50,000 civilian non-institutional households. In year 2000, for example, roughly 51,000 households were sampled throughout the United States, including about 1,900 within the County of Los Angeles. In year 2000, however, there were over 105 million occupied households in the nation with more than 3.1 million in Los Angeles County. (The Census Bureau defines a household as consisting of a single individual or a group of people occupying a common housing unit, whether related or not.) Excluded from the CPS are persons living in college dorms and military base housing (barracks), as well as patients and inmates of institutions. Undocumented aliens and the homeless are also not counted. Further, the CPS excludes residents of Puerto Rico and other outlying areas of the U.S. -- such as Guam, the Virgin Islands, American Samoa and the Northern Mariana Islands.

Annual CPS poverty data are reported separately for the nation, regions, a few large counties and an aggregation of the 10 largest metropolitan areas. Due to the small samples, poverty at state levels are reported only as 2-year and 3-year moving averages. The data are categorized by race and Hispanic ethnicity, where Hispanics are double-counted also by race. These categories currently consist of: Asians, Blacks, Hispanics (of any race), Native Americans, Native Hawaiians \& Other Pacific Islanders, Non-Hispanic Whites, Some Other Race, Two or More Races and Whites. Annual demographic statistics on poverty are not at all reported for sub-national levels. Yet, even at the national level annual CPS statistics are highly erratic, unstable, volatile and unreliable.

The other primary source of official poverty statistics is the decennial census, with data obtained from all jurisdictional levels throughout the nation and U.S. Territories -- including states, counties, cities, towns, tracts and blocks. Data are collected and classified for many separate (but not necessarily mutually exclusive) demographic groups. Census poverty statistics are compiled from much larger samples than the CPS, consisting over the years of between $15 \%$ and $25 \%$ of all civilian non-institutional housing units. In Census 2000, for example, there were 17.6 million households in the national sample -- including over 522 thousand within the County of Los Angeles. Table 
1 presents year 2000 comparative statistics on populations, number of households and sample sizes used in both the CPS and the decennial census for the nation, the State of California and the County of Los Angeles.

Table 1

Year 2000 Samples

\begin{tabular}{|c|c|c|c|c|}
\hline Location & $\begin{array}{l}\text { Resident } \\
\text { Population }\end{array}$ & $\begin{array}{c}\text { Occupied } \\
\text { Households }\end{array}$ & $\begin{array}{c}\text { Occupied Households } \\
\text { in Decennial Census } \\
\text { Sample }^{1}\end{array}$ & $\begin{array}{c}\text { Occupied } \\
\text { Households in CPS } \\
\text { Sample }\end{array}$ \\
\hline United States & $281,421,906$ & $105,480,101$ & $17,580,017$ & 51,016 \\
\hline State of California & $33,871,648$ & $11,502,870$ & $1,917,145$ & 4,453 \\
\hline County of Los Angeles & $9,519,338$ & $3,133,774$ & 522,296 & 1,879 \\
\hline
\end{tabular}

The official definition of poverty was originally designed in 1963-64 by Mollie Orshansky of the Social Security Administration (Orshansky: Jan. 1965, July 1965, 1969). The definition and thresholds have provided a consistent measure of poverty since 1959 and were formally established in 1969 for use by all federal agencies. Poverty indexes are based upon pre-tax earned money income only and they currently vary according to the age of the head of the family and the number of family members. Before 1982, the index cut-off levels also considered the gender of the household head and whether the family resided on a farm. Annual changes in living costs are factored into the national poverty thresholds using the Consumer Price Index. But, there are no adjustments for regional variations in basic expenditures. And, since the cost of living in Los Angeles is about $23 \%$ higher than the national average, poverty is substantially underestimated for this metropolis (Bureau of the Census: 2000).

Figure 1 illustrates the changing official thresholds for a family of four, for example, over the relevant decennial census years (that is, for the years of poverty data used in this study). The thresholds have grown from $\$ 2,973$ in 1959 to $\$ 17,029$ in 1999 .

\section{Methodology \& Goals}

In this paper, estimates and projections of annual poverty are based upon the decennial census statistical tabulations for two reasons. First; because of their far larger sample sizes, decennial census estimates of poverty are more reliable and probably also more accurate. Second; Current Population Surveys do not report annual poverty for demographic groups at sub-national levels. Thus, yearly racial and Hispanic poverty statistics are not available from the CPS at the county level. Only the decennial censuses compile sub-state poverty data by demographic group and only at 10-year intervals.

Statistics from the decennial censuses provide discrete benchmarks that will be used to compute continuous smoothed trends in poverty for separate (but non-mutually exclusive) demographic groups within Los Angeles County. The universe of benchmark years consists of 1959, 1969, 1979, 1989 and 1999. Tables 2 and 3 list the officially tabulated rates and counts of poverty persons, respectively, for those years. These decennial statistics form the anchors for the independently computed trend lines.

Note that the actual years of poverty data all end with the digit 9. This is because the decennial censuses compile data on income and poverty for the immediate previous years. For example; during the year 2000 decennial census, income/poverty data were collected for calendar year 1999. Thus, 1999 is the most current year of decennial census poverty data. That is, the benchmark dates (ending in digit 9) are the years that income was received, not the census years that the data were obtained (ending in digit 0 ). 
Table 2

Decennial Census Poverty Rates Los Angeles County

\begin{tabular}{|c|c|c|c|c|c|}
\hline Group & 1959 & 1969 & 1979 & 1989 & 1999 \\
\hline All Persons & 13.0 & 10.9 & 13.4 & 15.1 & 17.9 \\
\hline Asians \& Pacific Islanders & $\mathrm{n} / \mathrm{a}$ & $\mathrm{n} / \mathrm{a}$ & 12.8 & 13.2 & 13.9 \\
\hline Asians & $\mathrm{n} / \mathrm{a}$ & $\mathrm{n} / \mathrm{a}$ & $\mathrm{n} / \mathrm{a}$ & 13.0 & 13.7 \\
\hline Hawaiians \& Pacific Islanders & $\mathrm{n} / \mathrm{a}$ & $\mathrm{n} / \mathrm{a}$ & $\mathrm{n} / \mathrm{a}$ & 19.6 & 23.2 \\
\hline Blacks & $\mathrm{n} / \mathrm{a}$ & 24.0 & 23.1 & 21.2 & 24.4 \\
\hline Children (related, under age 18) & $\mathrm{n} / \mathrm{a}$ & $\mathrm{n} / \mathrm{a}$ & 19.0 & 21.4 & 24.2 \\
\hline Elderly (age 65 and over) & $\mathrm{n} / \mathrm{a}$ & 17.1 & 9.2 & 9.2 & 10.5 \\
\hline Female Family Heads & $\mathrm{n} / \mathrm{a}$ & 28.0 & 26.9 & 26.5 & 28.5 \\
\hline Hispanics (of any race) & $\mathrm{n} / \mathrm{a}$ & 14.7 & 20.5 & 22.9 & 24.2 \\
\hline Native Americans & $\mathrm{n} / \mathrm{a}$ & $\mathrm{n} / \mathrm{a}$ & 17.0 & 17.1 & 22.5 \\
\hline Some Other Race & $\mathrm{n} / \mathrm{a}$ & $\mathrm{n} / \mathrm{a}$ & $\mathrm{n} / \mathrm{a}$ & $\mathrm{n} / \mathrm{a}$ & 26.0 \\
\hline Two or More Races & $\mathrm{n} / \mathrm{a}$ & $\mathrm{n} / \mathrm{a}$ & $\mathrm{n} / \mathrm{a}$ & $\mathrm{n} / \mathrm{a}$ & 20.1 \\
\hline Whites & $\mathrm{n} / \mathrm{a}$ & $\mathrm{n} / \mathrm{a}$ & 9.9 & 10.6 & 13.4 \\
\hline Non-Hispanic Whites & $\mathrm{n} / \mathrm{a}$ & $\mathrm{n} / \mathrm{a}$ & $\mathrm{n} / \mathrm{a}$ & 7.1 & 8.5 \\
\hline
\end{tabular}

Source: Bureau of the Census, U.S. Department of Commerce. 
Table 3

\section{Decennial Census Poverty Persons Los Angeles County}

\begin{tabular}{|c|c|c|c|c|c|}
\hline Group & 1959 & 1969 & 1979 & 1989 & 1999 \\
\hline All Persons & 771,547 & 752,554 & 984,816 & $1,308,255$ & $1,674,599$ \\
\hline Asians \& Pacific Islanders & $\mathrm{n} / \mathrm{a}$ & $\mathrm{n} / \mathrm{a}$ & 57,786 & 124,614 & 159,674 \\
\hline Asians & $\mathrm{n} / \mathrm{a}$ & $\mathrm{n} / \mathrm{a}$ & $\mathrm{n} / \mathrm{a}$ & 119,496 & 153,497 \\
\hline Hawaiians \& Pacific Islanders & $\mathrm{n} / \mathrm{a}$ & $\mathrm{n} / \mathrm{a}$ & $\mathrm{n} / \mathrm{a}$ & 5,118 & 6,177 \\
\hline Blacks & $\mathrm{n} / \mathrm{a}$ & 179,683 & 212,992 & 203,286 & 216,627 \\
\hline Children (related, under age 18) & $\mathrm{n} / \mathrm{a}$ & 291,939 & 375,214 & 482,514 & 626,757 \\
\hline Elderly (age 65 and over) & $\mathrm{n} / \mathrm{a}$ & 111,378 & 64,258 & 74,701 & 93,555 \\
\hline Female Family Heads & $\mathrm{n} / \mathrm{a}$ & 66,334 & 87,066 & 101,427 & 127,232 \\
\hline Hispanics (of any race) & $\mathrm{n} / \mathrm{a}$ & 187,168 & 419,277 & 744,383 & $1,012,455$ \\
\hline Native Americans & $\mathrm{n} / \mathrm{a}$ & $\mathrm{n} / \mathrm{a}$ & 9,101 & 7,225 & 15,096 \\
\hline Some Other Race & $\mathrm{n} / \mathrm{a}$ & $\mathrm{n} / \mathrm{a}$ & $\mathrm{n} / \mathrm{a}$ & $\mathrm{n} / \mathrm{a}$ & 579,657 \\
\hline Two or More Races & $\mathrm{n} / \mathrm{a}$ & $\mathrm{n} / \mathrm{a}$ & $\mathrm{n} / \mathrm{a}$ & $\mathrm{n} / \mathrm{a}$ & 96,232 \\
\hline Whites & $\mathrm{n} / \mathrm{a}$ & $\mathrm{n} / \mathrm{a}$ & 496,943 & 523,435 & 607,313 \\
\hline Non-Hispanic Whites & $\mathrm{n} / \mathrm{a}$ & $\mathrm{n} / \mathrm{a}$ & $\mathrm{n} / \mathrm{a}$ & 248,163 & 245,519 \\
\hline
\end{tabular}

Smoothed trend lines will be created by quadratic curvilinear regressions using data for the years 1979, 1989 and 1999 only (from the decennial censuses of 1980, 1990 and 2000) and then extrapolated a decade to year 2009 -- when a new set of benchmarks will be established by the census of 2010. The explanatory variable is the year of earned income and the data fit of each respective polynomial regression is intentionally designed to be "perfect." Hence, each specific regression equation will yield an r-square of $100 \%$ and a standard error of zero -since each parabolic trend line will intersect all three plotted data points for a demographic group. Ideally, the model would connect every data point within the universe of five decennial census dates. Such a model, however, would generate insurmountable multicollinearity among the terms.

Two versions of the trend lines will be created and projected. One set will trace the poverty rates of each demographic group, where the incidence indicates the internal hardship faced by a particular demographic subpopulation. By contrasting the rates, we can compare the relative internal hardships experienced by the different groups. With numerical counts, however, we are looking at the aggregate hardship of poverty upon a group and its total impact upon the greater community. The numerical count of poverty is affected by the rate within the respective group as well as by the population size of that group.

The trend lines will contain an assortment of assumptions. For example; they assume that intervening years of poverty are accurately portrayed by smoothed temporal estimates. The projections further assume that the historical curvilinear trends will continue -- such as in rates of fertility, mortality and immigration. In addition; it is presumed that there will be no major disruptions in the trends due to wars, epidemics, natural disasters (such as an earthquake, fire or flood) or other special events. The independent variable "Year" serves as a collective proxy for a wide variety of economic, social, psychological and chance factors that can affect poverty rates over time.

It should again be emphasized that annual demographic poverty rates and counts are not estimated by any official source for sub-national jurisdictions. Although the CPS does provide annual poverty estimates for states, they are reported only for all demographic segments combined. These estimates are often disaggregated by the states despite the caution stated by the Census Bureau. But, by breaking down the overall statistics, the already low reliability of CPS annual poverty figures is further aggravated.

As also mentioned, neither the CPS nor the decennial census estimates of poverty make any regional adjustments for differential costs of living. Consequently, official poverty measures systematically and substantially 
underestimate poverty in Los Angeles. If such regional differentials were accounted for, both the rates and counts of County impoverishment would shift up. Yet, the upward shifts would not be uniform, as it is likely that some demographic groups would be affected more than others.

The methodology employed in this paper has been previously used by the author to estimate and project annual sub-national poverty -- such as for the State of California (Mogull: 1991 and forthcoming), for the State of Mississippi (Mogull: 2003), for the County of Sacramento (Mogull: 2004) and for the New York City metropolitan area (Mogull: 2004). This paper examines both rates and counts and incorporates the latest year 2000 decennial census data. The locale is the second most populous metropolis in the nation, with over 9.5 million County residents in year 2000. Los Angeles is also a major port of entry for diverse ethnic and racial groups, many of whom possess typical low-income characteristics of first-generation immigrants.

This paper has two broad goals -- to demonstrate a convenient technique to estimate and project annual poverty at the sub-national level and to focus on the unique demographics of the County of Los Angeles. The specific objectives are both to fill in for non-existent official data and to make projections by demographic group for the next decade. The methodology may be easily applied at other jurisdictional levels and settings.

\section{The Evidence}

\section{The Past}

Figures 2 and 3 below are plots of the universe of decennial census poverty statistics for Los Angeles County for each separate demographic group. These statistics were reported in Tables 2 and 3 . The data points are connected by lines in order to facilitate a visual comparison both of levels and of trends among the various groups. (The connecting lines are not created by regressions.)

From an examination of the official poverty rates in Table 2/Figure 2, we find that:

- $\quad$ Over the 40 years that poverty levels have been measured, the overall County poverty rate has increased $38 \%$-- from $13.0 \%$ in 1959 to $17.9 \%$ in 1999 . Thus, the incidence of poverty has become far more prevalent within the County population. During the decade of the 1960 s, the poverty rate declined $16 \%$. It surged, however, by 23\%, $13 \%$ and then $19 \%$ over the next three decades.

- $\quad$ Among Asians \& Pacific Islanders, the rate of poverty has increased almost 9\% -- from $12.8 \%$ in 1979 to $13.9 \%$ in 1999. During the 1990s, rates among Native Hawaiians \& Other Pacific Islanders alone rose $18 \%$, from $19.6 \%$ in 1989 to $23.2 \%$ in 1999 . Among Asians alone, poverty rates grew just 5\%, from $13.0 \%$ to $13.7 \%$. Thus, rates for Native Hawaiians \& Other Pacific Islanders alone have far exceeded those for Asians alone.

- $\quad$ Black poverty rates have barely risen over the three decades of measurement, from $24.0 \%$ in 1969 to $24.4 \%$ in 1999. After declining during the 1970 s and 1980 s, their rates caught up by jumping $15 \%$ during the 1990s. Traditionally, the incidence of poverty among Blacks has been the highest of all races.

- $\quad$ The incidence of poverty among Children (related and under age 18) rose more than $27 \%$ over two decades, from $19.0 \%$ in 1979 to $24.2 \%$ in 1999 .

- $\quad$ The Elderly (age 65 and over) is the only demographic group to experience an overall poverty decline -from $17.1 \%$ in 1969 to $10.5 \%$ in 1999. The greatest drop occurred during the 1970 s, when there was a $46 \%$ fall from $17.1 \%$ to $9.2 \%$. Although the 1980s saw no change, between 1989 and 1999 rates rose $14 \%$ from $9.2 \%$ to $10.5 \%$. Elderly poverty rates are among the lowest of all measured demographic groups.

- $\quad$ Rates for Female Family Heads (FFH) have been the highest among all groups over the past three decades. There were very slight temporal variations, rising only $2 \%$ from $28.0 \%$ to $28.5 \%$ between 1969 and 1999 .

- $\quad$ Hispanic poverty rates have risen a steep 65\% between 1969 and 1999, from $14.7 \%$ to $24.2 \%$. The rate of increase, however, has tapered off greatly -- from $40 \%$ during the 1970s to $12 \%$ during the 1980 s and just $6 \%$ during the 1990s. Nevertheless, their rates are among the highest of all demographic groups and, by 1999, the incidence of Hispanic poverty almost matched the high rates of Blacks. 
- $\quad$ Poverty among Native Americans grew 32\% over the past two decades, from $17.0 \%$ in 1979 to $22.5 \%$ in 1999. Although there was virtually no change during the 1980s, their rates jumped $32 \%$ during the 1990s.

- $\quad$ There is just one year's measurement for Some Other Race. In 1999, their $26.0 \%$ poverty rate was higher than for any other race. Only the rate of FFH exceeded that of Some Other Race.

- $\quad$ Two or More Races also experienced a relatively high poverty incidence in 1999 at $20.1 \%$.

- $\quad$ Poverty rates for all Whites rose $35 \%$ over the 1980 s and 1990 s, from $9.9 \%$ to $13.4 \%$. For Non-Hispanic Whites alone, there was a smaller $20 \%$ rise during the 1990 s, from $7.1 \%$ to $8.5 \%$. Despite the increase, the incidence of poverty among Non-Hispanic Whites was lower than for any other measured demographic group.

Figure 3 plots the number of impoverished residents by demographic group for the universe of decennial census poverty statistics. Table 3/Figure 3 contribute to a more complete picture of historical poverty for Los Angeles County.

The evidence shows that:

- $\quad$ Over the past four decades, the total number of impoverished individuals within the County rose $117 \%$ or by about 3\% per year, from almost 772 thousand in 1959 to 1.7 million in 1999. After declining $2.5 \%$ during the 1960s, the number poor grew a startling $30 \%$ within each of the next three decades.

- Impoverished Asians \& Pacific Islanders expanded a sharp 176\% between 1979 and 1999 or by almost 9\% per year -- from 58 thousand to 160 thousand. As a consequence, their share of overall County poverty jumped from $5.9 \%$ to $9.5 \%$, with a far greater rate of increase during the $1980 \mathrm{~s}$ than the $1990 \mathrm{~s}(116 \%$ versus 28\%). The poverty increase for Asians alone during the 1990s was $29 \%$, while the increase for Native Hawaiians \& Other Pacific Islanders alone was 21\%. (In 1999, Asians accounted for $96.1 \%$ of the total poor of this combined category.)

- $\quad$ Black poor grew $21 \%$ between 1969 and 1999 or by a modest .7\% average increase per year -- from 180 thousand to 217 thousand. Their share of overall County poverty has receded continuously. Whereas Blacks accounted for $23.9 \%$ of the total County poor in 1969, by 1999 they represented just $12.9 \%$.

- $\quad$ Poor Children have expanded by $115 \%$ over the past three decades or by about $4 \%$ per year -- from 292 thousand to 627 thousand. The growth from decade to decade has risen by $28.5 \%, 28.6 \%$ and $29.9 \%$. Their share of the overall County poor has remained at roughly $38 \%$.

- $\quad$ The Elderly poor shrank 16\% between 1969 and 1999 -- from 111 thousand to 94 thousand. As a proportion of the total County poor, the Elderly have plummeted from $14.8 \%$ to just $5.6 \%$. The entire decline occurred during the $1970 \mathrm{~s}$, when their numbers dropped by $42 \%$. The increases during the $1980 \mathrm{~s}$ and the 1990 s were $16 \%$ and $25 \%$, respectively.

- $\quad$ Poor Female Family Heads rose $92 \%$ between 1969 and 1999 or by 3\% per year -- from 66 thousand to 127 thousand. Yet, their share of the total poor has dropped from $8.8 \%$ to $7.6 \%$.

- The number of impoverished Hispanics within the County presents a unique picture. Over the three decades of measurement, Hispanic poor shot up $441 \%$ or by an average annual increase of almost $15 \%$. In 1969, the number of Hispanic poor was 187 thousand and accounted for "just" $24.9 \%$ of overall County poverty. Thirty years later, there were over one million Hispanic poor and represented $60.5 \%$ of all County poverty. The percentage increases in Hispanic poor persons, however, have steadily declined from $124 \%$ during the 1970s to $78 \%$ in the 1980 s to $36 \%$ in the 1990s. As revealed in Figure 3, the slopes for the All Persons and the Hispanic trend lines are roughly parallel, indicating a very close historical association between the two categories. Thus, overall poverty numbers within the County have been tied primarily to changes in the Hispanic poor.

- $\quad$ Native American poverty numbers have risen $66 \%$ over the 20 years of measurement or by a $3 \%$ average annual increase -- from nine thousand in 1979 to 15 thousand in 1999. Although there was a 21\% drop during the 1980s, the 1990s saw a 109\% leap. Their share of overall County poverty began and ended at $.9 \%$.

- $\quad$ The Some Other Race category has just one year of measurement. Their 580 thousand poor persons accounted for a very substantial 34.6\% share of all County poor in 1999. 
- $\quad$ There were 96 thousand impoverished persons of Two or More Races in 1999, which represented 5.7\% of the total number poor in Los Angeles County.

- $\quad$ The number of Whites beneath poverty thresholds rose $22 \%$-- from 497 thousand in 1979 to 607 thousand in 1999 or by a $1 \%$ average annual increase. Their rate of growth jumped from 5\% during the 1980 s to $16 \%$ during the 1990s. Yet, as a proportion of overall County poor, Whites accounted for continuously shrinking shares -- from $50.5 \%$ in 1979 to $40 \%$ in 1989 to $36.3 \%$ in 1999 . The number of poor NonHispanic Whites fell 1\% between 1989 and 1999 -- from 248 thousand to 246 thousand and their share of the total poor receded accordingly from $19.0 \%$ to $14.7 \%$.

\section{The Present}

Before looking to the future, let us examine the most current decennial census snapshot of poverty within Los Angeles County. Figure 4 provides a cross-sectional comparative illustration of poverty rates among the various demographic groups. The overall incidence of poverty across all demographic groups in 1999 is $17.9 \%$. In descending order, those segments with the highest incidences are: Female Family Heads (28.5\%), Some Other Race (26.0\%), Blacks (24.4\%), Hispanics (24.2\%), Children (24.2\%), Native Hawaiians \& Other Pacific Islanders alone (23.2\%), Native Americans (22.5\%), Two or More Races (20.1\%), Asians \& Pacific Islanders combined (13.9\%), Asians alone (13.7\%), Whites (13.4\%), the Elderly (10.5\%) and Non-Hispanic Whites (8.5\%).

Table 4 reports and Figure 5 illustrates each demographic group's latest decennial census shares of total poverty and total population within the County. For example: although Hispanics represent $44.6 \%$ of the overall population, they account for $60.5 \%$ of all poverty persons. Table 4 further presents the ratio of each group's share of poverty to share of population. The purpose of the right-hand column is to determine whether a group accounts for its "fair" share of overall poverty -- where a value of one indicates an "appropriate" share, a ratio greater than one indicates an "excessive" share and a ratio of less than one indicates an under-representative share. 
Table 4

Poverty \& Population Shares Los Angeles County

\begin{tabular}{|c|c|c|c|c|c|}
\hline Group & 19 & erty & 2000 & lation & Poverty \%/ \\
\hline & Persons & $\%$ of Total & Persons & $\%$ of Total & \\
\hline All Persons & $1,674,599$ & 100.0 & $9,519,338$ & 100.0 & 1.00 \\
\hline Asians \& Pacific Islanders & 159,674 & 9.5 & $1,164,553$ & 12.2 & .78 \\
\hline Asians & 153,497 & 9.2 & $1,137,500$ & 11.9 & .77 \\
\hline Hawaiians \& Pacific Islanders & 6,177 & .37 & 27,053 & .28 & 1.30 \\
\hline Blacks & 216,627 & 12.9 & 930,957 & 9.8 & 1.32 \\
\hline Children & 626,757 & 37.4 & $2,590,107$ & 27.2 & 1.38 \\
\hline Elderly & 93,555 & 5.6 & 926,673 & 9.7 & .57 \\
\hline Female Family Heads & 127,232 & 7.6 & 459,392 & 4.8 & 1.57 \\
\hline Hispanics & $1,012,455$ & 60.5 & $4,242,213$ & 44.6 & 1.36 \\
\hline Native Americans & 15,096 & .90 & 76,988 & .81 & 1.11 \\
\hline Some Other Race & 579,657 & 34.6 & $2,239,997$ & 23.5 & 1.47 \\
\hline Two or More Races & 96,232 & 5.7 & 469,781 & 4.9 & 1.16 \\
\hline Whites & 607,313 & 36.3 & $4,637,062$ & 48.7 & .74 \\
\hline Non-Hispanic Whites & 245,519 & 14.7 & $2,959,614$ & 31.1 & .47 \\
\hline
\end{tabular}

In descending order, those demographic groups which account for excessive shares of total County poverty are: Female Family Heads (with a ratio of 1.57), Some Other Race (1.47), Children (1.38), Hispanics (1.36), Blacks (1.32), Native Hawaiians \& Other Pacific Islanders alone (1.30), Two or More Races (1.16) and Native Americans 
(1.11). Those demographic groups with under-representative shares of overall County poverty are: Asians \& Pacific Islanders combined (.78), Asians alone (.77), Whites (.74), the Elderly (.57) and Non-Hispanic Whites (.47).

\section{The Future}

The future is presumed to be a reflection of the past. Projected poverty trends in both rates and counts assume a continuation of patterns that have been previously established. The historical patterns are derived from the most recent three decennial census years of poverty measurement only (1979, 1989 and 1999). Quadratic polynomial regression models are employed to reveal the underlying curvilinear trends, where "Year" is the controlling variable. Table 5 presents the computed regression coefficients.

Table 5.

Quadratic Regression Estimates Los Angeles County

Group
All Persons
Asians \& Pacific Islanders
Blacks
Children
Elderly
Female Family Heads
Hispanics
Native Americans
Whites

All Persons

Asians \& Pacific Islanders

Blacks

Children

Elderly

Female Family Heads

Hispanics

Native Americans

Whites

\begin{tabular}{ccc} 
Intercept & \multicolumn{2}{c}{ Coefficient } \\
\cline { 2 - 3 } Poverty Rates & First Degree & Second Degr \\
& & \\
21326.2 & -21.654 & 0.0055 \\
5837.99 & -5.912 & 0.0015 \\
100773.0 & -101.374 & 0.0255 \\
7416.5 & -7.696 & 0.002 \\
25594.7 & -25.792 & 0.0065 \\
47340.8 & -47.656 & 0.012 \\
-22103.7 & 22.064 & -0.0055 \\
104307.0 & -105.142 & 0.0265 \\
41201.8 & -41.594 & 0.0105 \\
& & \\
Poverty Persons & & \\
& & \\
$7.81396 \mathrm{E} 8$ & -818891.0 & 214.525 \\
$-6.38398 \mathrm{E} 8$ & 636960.0 & -158.84 \\
$4.55725 \mathrm{E} 8$ & -458223.0 & 115.235 \\
$7.06221 \mathrm{E} 8$ & -722219.0 & 184.715 \\
$1.63536 \mathrm{E} 8$ & -165830.0 & 42.055 \\
$2.22476 \mathrm{E} 8$ & -225613.0 & 57.22 \\
$-1.18641 \mathrm{E} 9$ & $1.16407 \mathrm{E} 6$ & -285.17 \\
$1.92213 \mathrm{E} 8$ & -193568.0 & 48.735 \\
$1.12468 \mathrm{E} 9$ & $-1.13589 \mathrm{E} 6$ & 286.93 \\
& &
\end{tabular}

To demonstrate how the specific regression equations yield annual estimates and projections, we can look at examples for All Persons. Projections of the rate and the number of impoverished County residents in year 2009 are:

$$
\begin{aligned}
& \text { - } \quad \text { Poverty Rate }=21,326.2-21.654(2009)+0.0055(2009)^{2}=21.8 \% \\
& \text { - } \quad \text { Poverty Number }=781,396,000-818,891(2009)+214.525(2009)^{2}=2,084,258
\end{aligned}
$$

Smoothed trends with annual estimates are created for the time span 1979 through 2009 and are plotted in Figures 6 and 7.

From Figure 6, independent projections of demographic rates of poverty indicate some significant changes. In the coming decade 1999 to 2009 : the overall County poverty rate is projected to swell $21.8 \%$-- from $17.9 \%$ to 21.8\%; rates for Asians \& Pacific Islanders will rise 7.2\% to 14.9\%; Black rates will jump 34.0\% to 32.7\%; poverty 
rates for Children will grow $13.2 \%$ to $27.4 \%$; Elderly rates will rise $24.8 \%$ to $13.1 \%$; rates for Female Family Heads will expand $15.4 \%$ to $32.9 \%$; Hispanic poverty will edge up by $.83 \%$ to $24.4 \%$; Native American rates will leap $46.2 \%$ to $32.9 \%$; and poverty rates for Whites will jump $36.6 \%$ to $18.3 \%$.

Figure 7 indicates the independent demographic projections of counts of persons in poverty. Between 1999 and 2009, the total number of impoverished County residents will grow by $24.5 \%$ and reach almost 2.1 million persons. Poverty among Asians \& Pacific Islanders is seen to rise $2.4 \%$ to 164 thousand and, as a share of overall County poor, will drop from $9.5 \%$ to $7.8 \%$. The number of impoverished Blacks will increase $16.7 \%$ to 253 thousand and their share of total County poverty will fall from $12.9 \%$ to $12.1 \%$. Poverty among Children will grow $28.9 \%$ to 808 thousand and their share of the total poor will rise from $37.4 \%$ to $38.8 \%$. The Elderly poor will see a $29.2 \%$ growth to 121 thousand and will account for $5.8 \%$ of overall poverty, in comparison to $5.6 \%$ in 1999 . Poor Female Family Heads will grow $28.9 \%$ to 164 thousand and their share will rise from $7.6 \%$ to $7.9 \%$. The Hispanic poor are projected to increase $22.2 \%$ to 1.2 million, but their share will decline from $60.5 \%$ to $59.4 \%$. Native American impoverishment is seen to leap $120.6 \%$ to 33 thousand and will account for $1.6 \%$ of total poverty, compared to 0.9 a decade earlier. White poor will grow $23.4 \%$ to 750 thousand, but their share of overall County poverty will change little from about $36 \%$ in 1999.

\section{Summary \& Conclusions}

This study presents a method of estimating and projecting annual poverty at the sub-national level with the County of Los Angeles chosen as the demonstration locale. Using statistical benchmarks obtained from the decennial censuses, poverty for various demographic groups was traced. After examining the recent past for each separate group, independent demographic projections were extrapolated to year 2009. The goal has been to fill the void in annual poverty statistics at the sub-national level, where the methodology is shown to be easily replicated for other jurisdictional settings and levels. The evidence for Los Angeles County indicates that in the coming decade the aggregate rate of poverty is predicted to rise by $21.8 \%$ to $21.8 \%$. The total number of persons beneath poverty thresholds is predicted to surge by $24.5 \%$ and reach almost 2.1 million. There will be changes among demographic groups in their comparative poverty rates and in shares of overall County poverty. The evidence contained in this paper is hopefully of help to regional legislators and administrators and to public and private social service organizations.

\section{References}

1. Bureau of the Census, U.S. Department of Commerce, Washington, DC, <http://www.census.gov /hhes/www/poverty.html>.

2. Bureau of the Census, U.S. Department of Commerce, Statistical Abstract of the United States: 2000 (120 th edition), Washington, DC, 2000, Table 771, page 490.

3. Mogull, Robert G., "State Poverty: The Case of California," Journal of Social Service Research, forthcoming.

4. Mogull, Robert G., "Metropolitan Poverty: The Case of New York City," The American Economist, forthcoming in Fall 2004 issue.

5. Mogull, Robert G., "County Poverty: The Case of Sacramento," Journal of Applied Business Research, XX (Spring 2004), 51-62.

6. Mogull, Robert G., "Estimating \& Projecting State Poverty: The Case of Mississippi," Journal of Business and Economic Perspectives, XXIX (Fall/Winter 2003), 70-78.

7. Mogull, Robert G., “Annual Estimates of California’s Poor: 1959 Through 1990,” American Journal of Economics and Sociology, L (July 1991), 299-312.

8. $\quad$ Orshansky, Mollie, "How Poverty is Measured," Monthly Labor Review, XCII (Feb. 1969), 37-41.

9. Orshansky, Mollie, "Who's Who Among the Poor: A Demographic View of Poverty," Social Security Bulletin, XXVII (July 1965), 3-32.

10. Orshansky, Mollie, "Counting the Poor: Another Look at the Poverty Profile," Social Security Bulletin, XXVIII (Jan. 1965), 3-29. 